\title{
Formation favorable, economically safe ecological environment and ensuring sustainable development
}

\author{
Gennady Alexandrov, and Alexander Yablonev* \\ Tver State Technical University, 170026 Tver, Russia
}

\begin{abstract}
This publication examines the implementation of the concept of sustainable development, which are increasingly becoming the object of research by scientists and practitioners. At the same time, special attention should be paid to the important fact, that, in practical terms, the solution of this problem is largely due to the formation of an economically safe and, as a consequence, favorable from the standpoint of the interests of entrepreneurs, an eco-environment, that provides their motivation for sustainable development. The study pays mainly attention to the development of an algorithm for solving methodological issues concerning, firstly, the essence and relationship of such concepts, as sustainable development and an economically safe business environment, favorable for investing in innovative processes. Secondly, the analysis of the ecological environment, as a systemic education and positioning in this system of the regional business environment. Thirdly, the development of approaches to the creation of a method for diagnosing the ecological environment, identifying and assessing the factors, that determine its economic security. Fourthly, the assessment of these factors in the form of an unsystematic component of investment risk. And, fifthly, which is important in practical terms, justifying the possibility in the reverse order, relying on the diagnostic results obtained, to determine, develop and implement specific measures to eliminate various kinds of factors, that negatively affect the formation of an economically safe ecological environment and, accordingly, on the development of an innovative activities and revitalization of investment processes, leading to the achievement of the SDGs.
\end{abstract}

\section{Introduction}

The appeal to the problem of implementing the Concept of Sustainable Development was updated, first of all, by the fact, that in the nineties of the last century, the World Commission on Environment and Development (WCED) presented a Report, entitled "Our Common Future" [1]. It views sustainable development as a process of harmonious, balanced development of economic, social and environmental practices. This presupposes the consistency of such interim measures in the implementation of the concept, as the use of

\footnotetext{
*Corresponding author: alvovich@mail.ru
} 
natural resources, investments, scientific and technological advances, along with personal development and institutional changes, with the goal of strengthening current and future potential in order to meet human needs and aspirations. To date, as noted in the World Investment Report 2020 published by the United Nations Conference on Trade and Development (UNCTAD), more than 150 countries have adopted national sustainable development strategies or revised existing development plans in line with the SDGs [2]. At the same time, the progress of investing in the Sustainable Development Goals (SDGs) sectors, especially in developing countries, remains too small, and the investment policy related directly to the SDGs is not being implemented quickly enough [2]. To add to the rationale for relevance, the existing investment promotion instruments applicable to the SDGs, as confirmed by the UNCTAD analysis of national investment policy regimes, are limited in number and do not meet the requirements of a systems approach. And in addition, less than half of the UN member states have specific instruments to promote investment in the SDGs. At the same time, on average, each of them provides for regulatory measures in no more, than three sectors or areas of activity, related to the SDGs. Many other countries do not have such measures at all [2]. An additional urgency to the problem is added by the fact, that from the very beginning of the discussion about the need for a transition to sustainable development, the question was raised about the objective difficulties and existing disagreements about the ways of combining economic growth with environmental goals, identified in the course of the practical implementation of this concept [3,4]. At the same time, one should also point out a critical attitude towards the very principles of the concept, behind which lies the desire to establish international dominance of economically developed countries, market inequality or the traditional hierarchy of power, reminiscent of the colonial era [5]. However, the main thing, that determines the relevance of the problem under consideration, is the possibility of the emergence of unacceptable investment risks due to the established environmental and social restrictions on the economic activities of entrepreneurial structures. This may well have a negative impact on the investment attractiveness and motivation to invest. It is clear, that there is a problem of resolving this contradiction in order to ensure the consistency of economic interests, on the one hand, and socio-ecological, on the other, without which the implementation of the SDGs becomes very problematic. Moreover, as noted in the WCED Report, too much emphasis on economic growth in fairly well-developed countries suggests a typical business approach, accompanied by only minor adjustments to reduce the impact of industries, in particular, on the environment, and it is indicated, that in order to solve global problems, ensuring sustainable development, much more radical approaches are required [1].

Today, many countries around the world have their own programs for the transition to sustainable development. As for the Russian Federation, the Concept of the Transition to Sustainable Development was adopted in 1996 (Presidential Decree No. 440 of 01.04.1996). It envisageds for a consistent transition to sustainable development, providing a balanced solution to socio-economic problems and problems of preserving a favorable environment and natural resource potential in order to meet the needs of present and future generations of people. It is especially important to emphasize, that innovation and investment activities are defined as a priority goal, aimed, first of all, at creating favorable conditions for the concentration of investment resources and conditions for the development of competition, ensuring the attraction of investments into the economy of the Russian Federation. Note, that the issue of attracting investments for the implementation of the SDGs in the Russian Federation is also relevant due to the fact, that the expectation, that the "invisible hand of the market", in the figurative expression of A. Smith, will automatically lead to motivation of entrepreneurs to invest and innovation has not been justified. The business environment, in which business entities are located, is slowly changing towards creating favorable conditions for their activities. And, as the practice of the formation of market relations shows, the 
enterprises themselves often do not provide a sufficient level of their own economic security and are unable to adequately respond to external threats, challenges and all kinds of barriers and restrictions, and even more so to resist them. At the same time, one should take into account the presence of an objective contradiction inherent in a market economy, namely, between the planned organization of production at individual enterprises and a competitive and conjunctural, and therefore chaotic, market environment. Ultimately, this contradiction manifests itself in an unacceptable amount of investment risk, which can become a significant obstacle to innovation and investment, including those, that should ensure the implementation of the SDGs. As a result, all of the above indicates the need to address a number of methodological issues, that could serve as the basis for analyzing the business environment, substantiating the directions of its formation as economically safe and attractive for attracting innovations and sustainable investments, that can ensure the implementation of the Concept of Sustainable Development.

\section{Materials and Methods}

As noted above, there are disagreements about the essence and content of the Concept of Sustainable Development itself. This is especially true in the opposition of the economic growth and sustainable development concepts. The WSED Report argues, that economic growth in relation to rich countries, as a mechanism for solving the set task, may not work at all, since it does not take into account other parameters of sustainable development, which are represented by the three English E: economics - sustainable economic growth; environment - sustainably functioning nature (natural environment); equity - sustainable social equality. Development or growth? Is it worth opposing? Growth, according to the authors of the report, is aimed at a quantitative increase in the scale of the economy in its physical dimension, and development presupposes qualitative improvements in the structure, design and composition of physical volumes and flows. And further, growth is more, and development is better. "The time has come, - as noted in the Report, - to destroy the past patterns" [1]. But why destroy, if in the very principle of the three E's, economics means sustainable economic growth. That's right - growth. Moreover, since the times of A. Smith, D. Ricardo and then K. Marx, the concept of extensive and intensive types of expanded reproduction (read - growth), expanded extensively, if the "field of production" expands, and intensively, if "more effective means of production are used" [6]. Therefore, it would be theoretically correct not to oppose sustainable development to economic growth, but to consider economic growth as sustainable if it is carried out, as it is now customary to say, on an innovative basis and meets the principles of the other two $E$. In other words, it is quite possible to achieve, that there were both "more" and "better", but also not exclude the possibility of ensuring development without quantitative growth, that is, "better", but "without more" and on an innovative basis. However, as noted earlier, the resolution of existing contradictions and problems with the implementation of the Concept of Sustainable Development acquires practical meaning only when it is considered within the framework of a specific business environment and assessment of its state in terms of attractiveness for attracting sustainable investments. Recently, within the framework of the Concept of Sustainable Development, the business environment is considered as an ecological environment (from the Greek "Oikeo", which has several meanings: I live, I inhabit, as well as location, populated area, habitat, etc.). In fact, the ecological environment is a form manifestation of its substance, that is, the business and investment climate. Therefore, the state of this substance and, accordingly, the business motivation for sustainable investments depends on how attractive, safe the current ecological environment is, and does not bear risks, that go beyond acceptable limits. A complete picture of what the eco-environment is in essence can be understood only from the standpoint of a systems approach. Moreover, in fact, 
it is, a vertical hierarchical system, which includes levels: enterprise - industry (type of activity) - territorial entity (region) and, accordingly, country, that is, macro level (for more details about the tiered environment, see [7]). Thus, the eco-environment as a whole is a system, in which the primary links of the economy - enterprises - are created, functioned and developed. As E. Helfert ("Financial analysis techniques") quite rightly notes, in this respect it is important to determine what influence the external environment and the peculiarities of "... the sphere or spheres of activity, in which the company operates, have on its attractiveness. Moreover, this is also influenced by the general economic conditions". To this can be added the fundamental consideration, expressed in the fundamental work of $F$. Evans and D. Bishop, that when assessing a specific company it is necessary "to take into account the results of the analysis of the competitive conditions of the company, including external industry and internal factors ..." [8]. And, since innovation and (or) investment projects are carried out directly in this link, the attractiveness of an enterprise is determined by the situation, developing on the "upper floors" of the hierarchical economic vertical. At the same time, each of the subsystems, including the regional subsystem, can develop in opposite directions and manifest themselves in different ways, depending on the industry and the situation with the investment climate at the macro level. However, the situation with the investment climate and, accordingly, with the ecological environment, can be assessed only in the process of diagnosing the state of affairs with economic security and with those factors, that we consider as barriers and restrictions, threats and challenges, that negatively affect economic security. This influence is that these factors are the substance of risk, the magnitude of which can exceed its acceptable value and, thereby, become an insurmountable obstacle to investing in innovation and in the SDGs.

\section{Results and Discussion}

The solution to the problems considered in this study is complicated by the fact, that the ideas about the phenomenon of economic security and its place in the formation of an ecoenvironment attractive for sustainable investments remain largely controversial. It is important to emphasize, that here we are guided by the hypothesis, that an economically safe ecological environment, from the point of view of business entities, is an environment, that causes an acceptable risk and, thus, is considered by them as favorable for innovation and investment. However, others, primarily foreign authors, defend the idea, that this concept refers only to the national level, and in such aspects as: countering threats to the country's defense, ensuring the protection of people's lives and improving the quality of their living standards $[9,10]$; ensuring the safety of socio-economic systems and their protection from the risk of loss of well-being in conditions of limited resources [11]; business revitalization [12]; obtaining additional benefits both by the state and by business [13]. The originality of our approach lies in the fact, that we present the category of "economic security" as the most important component of investment attractiveness, and consider it as an objective-subjective phenomenon, that is revealed in a combination of various kinds of factors and essential aspects. We will consider them below. As for the objective nature of the category under consideration, it is due to the investment climate, formed in the ecological environment, at its hierarchical levels and at this time. At the same time, economic security, as a form of manifestation of the investment climate, is largely determined, firstly, by the stability or immunity of each level, that is, a kind of immunity to the effects on them of various kinds of external negative factors inherent in the market economy itself; secondly, their resistance, that is, the ability to resist such an impact; and thirdly, the ability to find and eliminate all sorts of internal causes of negative trends, that adversely affect their immunity and resistance in order to avoid possible damage, if possible completely or at least partially. At the same time, as for the subjective side of the phenomenon of "economic security", it is ultimately 
determined by the attitude of specific entrepreneurs, who are the subjects of assessment to it, taking into account their interests, their self-perception of the ecological environment and their own status in society, in the possibility of opening a new business with an acceptable level of risk and without fear of failure and, in general, in accordance with their intentions $[14,15]$. Naturally, the same kind of perception is characteristic of other subjects of appraisal, a potential partner, an external investor, who have large alternatives and a wider choice of investment objects, differing in specific types of activity and location. It is clear, that the subjects of the assessment should be armed with a specific method and practical methodology, with the help of which it would be possible to diagnose the situation with economic security and, in general, assess the attractiveness of the ecological environment in order to assess the risks and, on this basis, make a decision on investment. However, this can be done only on the basis of understanding in what form, how and at what hierarchical level barrier and restrictive factors, threats and challenges, that characterize the state of economic security of the ecological environment are manifested and, accordingly, what is the magnitude of investment risks, or rather their non-systematic part, in which these factors materialize. In this regard, first of all, it is proposed, on the basis of the principle of identification and differentiation, to form four species groups of factors, based on the corresponding characteristics. Then highlight the most significant factors in order to integrate them into the appropriate groups, that characterize each of the levels of the economic hierarchy. The formation of enlarged groups of factors is based on the theoretical proposition, that any mode of production is a unity of productive forces and production relations. The first are characterized by the technical and technological level of the means of labor, the quality of the labor force, and the social and environmental conditions of production. The second are superstructure organizational and economic relations, which are a modification of objective economic relations and are regulated by administrative and legal methods and mechanisms through appropriate institutions. Thus, it is possible to form on this basis four groups of factors: economic, administrative-legal, resource-technical and socio-ecological. And it is easy to see, that their content, due to various kinds of threats and challenges, barriers and restrictions, is quite correlated with the principles of the three $E^{\prime} s$, which are the basis of the Concept of Sustainable Development, which confirms the adequacy of the approach. Since the ecological environment, considered by us, on the one hand, as a systemic integral formation of its levels: enterprise - industry - region - national economy (country level), and, on the other hand, as factors, combined into groups, that characterize these groups at each of the hierarchical levels, then it becomes possible to present it as a systemic formation of a higher order, that is, in the form of a sixteen-cell diagnostic matrix model "levels-factors" (four levels into four groups of factors). Thus, a toolkit is being built for diagnosing and assessing economic security and investment attractiveness of both the ecological environment as a whole and each of its level components. However, the use of such tools makes it necessary to determine the so-called "effective set" of those factors, that affect economic security and investment attractiveness in order to assess the "contribution" of each of the sixteen combinations of "levels - factors" in the formation of the value of the nonsystematic component of investment risk. In this regard, solving the issue of identifying and differentiating factors becomes especially relevant, when creating tools for diagnosing investment attractiveness and, accordingly, the non-systematic component of investment risk, the assessment of which is necessary for entrepreneurs to make an economically balanced investment opinion. Due to the limitations of the article, we do not have the impossibility to present this toolkit in a formalized form, that is, in the form of a model, as well, as to outline the technology of its use for diagnosing the ecological environment and determining the possibilities of making sustainable investments and innovations in the SDGs (one of the options for using this methodological approach in relation to the assessment of the economic security of the enterprise and its investment attractiveness on the example of 
the extractive industry [7]).This level-factor approach should provide an opportunity to analyze and evaluate economic security and investment attractiveness, so that, firstly, a potential investor, based on the results of diagnostics, can make a reasoned decision on investment; secondly, the invested entrepreneur could get a real idea of the factors and trends, that negatively affect the investment attractiveness of his business; thirdly, all business entities, that, at their level, manage the processes of forming an investment climate (including an investing entrepreneur), could decide on measures, the implementation of which would contribute to the elimination of everything that negatively affects its attractiveness.

\section{Conclusion}

In conclusion, we note, that the methodological approach to diagnostics, assessment and formation of an economically safe ecological environment developed in the course of the study is a theoretical basis for the creation of appropriate tools intended specifically: firstly, for assessing economic security and, accordingly, the attractiveness of the ecological environment as a whole and, in particular, each level, including the regional one, which we consider, as well as other levels, only as relatively independent, that is, as a subsystem in the overall ecosystem. Secondly, to obtain initial information about the barrier and restrictive factors, threats and challenges, that negatively affect the economic security and investment attractiveness of the regional ecological environment. And thirdly, for the development of specific measures of a superstructure (organizational and economic) nature, aimed at eliminating and (or) mitigating the negative manifestation of a number of factors, that cause risks to go beyond acceptable levels and, thereby, facilitate the attraction of sustainable investments for the implementation of the SDGs. In addition, the results of the study will, in our opinion, make it possible to significantly advance both in theoretical and practical terms in the development and implementation of reasonable measures to ensure economic security and the formation of an environment favorable for sustainable investments at all levels of the economic hierarchy, including the regional level.

The reported study was funded by RFBR, project number 20-010-00124: "Improving the concept of economic security and assessing the level of its security in the aspect of investment attractiveness of enterprises".

\section{References}

1. World Commission on Environment and Development, Our Common Future (Oxford University Press, Oxford, 1987)

2. World Investment Report 2020, International Production Beyond the Pandemic (UN Publications, New York, 2020)

3. R. Costanza, C. Folke, Ecological Economics and Sustainable Development (Manila, Philippines, 1994)

4. Political Economy of the Environment (Training Kit, Washington, 1996)

5. D. Chandler, Int. J. of Secur. and Devel., 4(1), 1 (2015)

6. K. Marx, Capital. Critique of Political Economy (Verlag von Otto Meissner, Hamburg, 1885)

7. G. Alexandrov, A. Iablonev, E3S Web of Conf., 174, 04013 (2020)

8. C. Evans, D.M. Bishop, Valuation for M\&A: Building Value in Private Companies (John Wiley\&Sons, Inc., New York, 2009)

9. M.M. Kevin, R.H. Topel, Americ. Econ. Rev, 103, 508 (2013) 
10. I. Selahattin, S. Kitao, Americ. Econ. J.: Macroecon, 4, 96 (2012)

11. Lee H. Endress, Sustainable Economic Development. Resources, Environment and Institutions (Academic Press, USA, 2015)

12. M.S. Castaño, M.T. Méndez, M.A. Galindo, J. of Bus. Res, 11, 5280 (2016)

13. E. Autio, H. Rannikko, Research Policy, 1, $42-55$ (2016)

14. M.J. Beynon, P. Jones, D. Pickernel, J. of Bus. Re, 89, 418 (2018)

15. S. Stroe, V. Parida, J. Wincent, J.of Bus. Res, 89, 265 (2018) 